\title{
Teorías afectivas vintage. Apuntes sobre Deleuze, Bergson y Whitehead
}

\author{
Vintage Affective theories. Notes on Deleuze, Bergson and Whitehead
}

Dr. Ali Lara (alara@gc.cuny.edu) Sociology Department, City University of New York (New York, USA)

\begin{abstract}
The 'Affective Turn' has generated a change in the production of knowledge based on certain philosophical trends recognized as 'process philosophies'. Giles Deleuze, Henri Bergson and Alfred North Whitehead are some exponents of those philosophies that have strongly influenced over the affect studies within social sciences. Their thinking has been even a condition of possibility for the current 'Affective Turn'. I will start this paper by arguing that these three authors of the process philosophies have shared a source of inspiration in the work of Baruch Spinoza. Later, I will present the ideas of Deleuze, Bergson and Whitehead that have been taken up -and recycled- by contemporary affect theorists. I will exemplify each case with a recent study from what I recognize as 'vintage affective theories'. I conclude with some reflections on the probabilities and improbabilities offered by this return to the process philosophy in affect studies developed by social sciences.
\end{abstract}

Key words: affective turn, vintage theories, process philosophies, Deleuze, Bergson, Whitehead

\section{Resumen}

El 'Giro Afectivo' ha generado un cambio en la producción de conocimiento sobre la base de ciertas tendencias filosóficas reconocidas como 'filosofías de los procesos'. Gilles Deleuze, Henri Bergson y Alfred N. Whitehead son algunos de los exponentes de estas filosofías que han influido con fuerza en los estudios del afecto al interior de las ciencias sociales. Su pensamiento ha sido incluso una condición de posibilidad para el actual 'Giro Afectivo'. Comenzaré este artículo argumentando que estos tres exponentes de las filosofías de los procesos tienen una fuente de inspiración compartida en la obra de Baruch Spinoza. Posteriormente expondré algunas de las ideas de Deleuze, Bergson y Whitehead que han sido retomadas -y recicladas- por los teóricos contemporáneos del afecto. Ejemplificaré cada caso con un estudio reciente de las que reconozco como 'teorías afectivas vintage'. Concluyo con una serie de reflexiones sobre las probabilidades e improbabilidades que ofrece esta vuelta a la filosofía de los procesos en los estudios del afecto que desarrollan las ciencias sociales.

Palabras clave: giro afectivo, teorías vintage, filosofías de los procesos, Deleuze, Bergson, Whitehead 


\section{Introducción}

La nostalgia ya no es lo que solía ser. Ahora está tan presente y renovada que comienza a parecerse a la esperanza. Un ejemplo claro de esto está en las nuevas teorías que incorporan ideas que habían sido parcialmente olvidadas -o por lo menos no consideradas fundamentales-, y a partir de las cuales generan un conocimiento novedoso que está basado en el reciclaje de teorías no muy recientes. Un gesto vintage. Tal es el caso de las formas de producción de conocimiento promovidas por el reciente 'Giro Afectivo' (Clough y Halley 2007). En otro lugar hemos argüido que el giro afectivo ha implicado "por un lado un reencuentro con algunas expresiones de las llamadas ciencias duras y por otra parte un cambio en las fuentes filosóficas que informan las teorías sociales" (Lara y Enciso 2013:112). El presente artículo se ocupa de clarificar las fuentes filosóficas que informan a los estudios contemporáneos del afecto en las ciencias sociales.

Como lo explica Edu Moreno, la vuelta a cierto tipo de filosofía por parte de los estudios del afecto y del Giro Afectivo guarda relación con el carácter crítico/reactivo frente a ciertas incomodidades dentro del auge del postestructuralismo/construccionismo; por ejemplo, hasta qué punto el interés por el papel clave del lenguaje y la organización social puede devenir, irónicamente, una obsesión que olvide al resto del mundo, y fundamentalmente, al cuerpo. De manera que, para estudiar el afecto, se hizo necesario recurrir a una filosofía que nos permitiera pensar en el cuerpo como tal, como materia y elemento de mediación orgánica, o como prefiere Patricia Clough, un cuerpo bio-mediado; y no ya como discursos o conjuntos de significados 'construidos' alrededor de ese cuerpo. Así, el desarrollo de los estudios contemporáneos del afecto precisó de una base filosófica diferente de aquella que sostuvo la época de esplendor del significado y lo simbólico en las ciencias sociales, y que generó comprensiones de la vida afectiva como epifenómenos sujetos a veces "a la cultura, al tiempo, el lengua, el idioma, o la estructura social" (Enciso y Lara 2014:283).

Las fuentes filosóficas a las que han recurrido los estudios del afecto han sido agrupadas por Paul Stenner (2011) bajo la etiqueta de 'filosofías de los procesos'. Una de las características comunes de dichas filosofías es la inspiración en la obra de Baruch Spinoza. Steven Brown y Paul Stenner proponen que dicha inspiración compartida se ancla en el desmantelamiento de la división mente-cuerpo establecida por Descartes, y que fue el punto central de la 'Ética' de Spinoza; en la que la visión cartesiana fue reemplazada por un sistema para el que "el objeto de la idea que constituye la mente humana es el cuerpo" (Spinoza, citado por Brown y Stenner 2001:84, traducción propia). Desde esta perspectiva, sugieren Brown y Stenner, la mente y el cuerpo no mantienen una relación lineal de control, de la primera sobre el segundo, como sugería Descartes, sino un paralelismo ontológico; luego "el orden y la concatenación de las cosas son uno y el mismo" (Spinoza, citado por Brown y Stenner, 2001:84, traducción propia).

Según Brown y Stenner, esta posición tiene dos efectos principales. Primero, "significa que aunque el pensamiento, considerado como atributo, es infinito, la mente esta por virtud de su constitución alrededor del 'objeto del cuerpo' localizada en la duración; es decir, como la aproximación a una forma particular de tiempo y espacio vivido" (2001:84, traducción propia, comillas del original). Segundo, 
continúan Brown y Stenner, Spinoza argumenta que: "La mente humana no tiene conocimiento del cuerpo humano, ni siquiera sabe que existe, más que a través de las ideas de modificación por las que el cuerpo es afectado" (Spinoza citado en Brown y Stenner, 2001:84, traducción propia). La importancia de estos dos efectos del pensamiento Spinoziano que Brown y Stenner subrayan, radica en que dicha visión "reúne el movimiento en ideas de modificación en el cuerpo, o para decirlo más claramente, el conocimiento sucede de forma paralela a los compromisos físicos del cuerpo" (Brown y Stenner 2001:84).

La idea cartesiana del cuerpo como simple vehículo de la mente no reflexionaba sobre las cualidades del cuerpo en tanto que tal, y este fue precisamente el foco de interés de la filosofía Spinoziana. Como él mismo afirmó: "Nadie ha determinado hasta ahora la potencia del cuerpo" (Spinoza, citado por Gregg y Seigwoth 2010:3). Sobre esta frase Melissa Gregg y Gregory Seigworth señalaron dos aspectos claves que son inmediatamente resaltables: primero, "la capacidad de un cuerpo nunca es definida por un cuerpo solo, sino está siempre en complicidad con, y encaja en, el campo o contexto de su fuerza-relación; y segundo, el 'aún no' del 'conocimiento del cuerpo' todavía está muy presente más de 330 años después de que Spinoza escribiera su Ethics. Pero, como Spinoza reconoció, el interés por lo que un cuerpo puede hacer, no se refiere a la figuración general del 'cuerpo' (cualquier cuerpo) sino, de manera mucho más singular, al intento por configurar un cuerpo y sus afectos/afectosidad, su actual composición afectiva de un mundo, la esto-sidad de un mundo y un cuerpo" (2010:3, traducción propia, comillas y paréntesis del original).

Para Spinoza, las formas en que los cuerpos pueden ser afectados y modificados son resultado de su potencia relacional, y están íntimamente ligados a la naturaleza de las relaciones y encuentros que los cuerpos experimenten. Brown y Stenner señalan que para Spinoza, las modificaciones que resultan de los encuentros pertenecen al orden de la emoción o afecto: "Por afecto entiendo las modificaciones del cuerpo por las cuales el poder de acción del cuerpo es incrementado o disminuido, ayudado o restringido, y al mismo tiempo la idea de esas modificaciones" (Spinoza, citado por Brown y Stenner 2001:89). A partir de esta concepción, "Spinoza evita lo que los modernos entenderíamos como la oposición entre emoción y cognición, al insistir en que los afectos son órdenes emergentes del campo relacional hechos en los encuentros entre cosas finitas reunidas" (Brown y Stenner 2001:89). En este entramado relacional las cosas finitas reunidas comprenden al mismo tiempo "un esfuerzo para mantener su forma y un potencial para conseguirlo" (Brown y Stenner 2001:88), esta es la idea de la capacidad de las cosas para afectar y ser afectadas, que se ha convertido en la moneda de cambio para los estudios contemporáneos del afecto.

La obra de Baruch Spinoza sería la base de, y/o ejercería gran influencia sobre, las filosofías de los procesos que surgirían en el siglo XX y que, como hemos dicho, constituyen la base de los estudios contemporáneos del afecto. Ahora bien, son tres los filósofos con raíces Spinozianas que abordaremos en este artículo: Gilles Deleuze, Henri Bergson y Alfred N. Whitehead. Ellos han sido reconocidos como las principales fuentes filosóficas del Giro Afectivo, su obra ha desencadenado líneas de pensamiento en los estudios del afecto, basadas siempre en el interés por el cuerpo como sede de encuentros y de devenires ontológicos, así como el compromiso anti-esencialista propio del pensamiento de Spinoza. Los 
elementos comunes en el pensamiento de nuestros tres filósofos, así como sus raíces Spinozianas, han sido reconocidos por diversos teóricos, por lo tanto no me enfocaré en vincularlos con Spinoza, ni en establecer similitudes entre sus ideas, más bien quiero resaltar los puntos de su obra que han servido de base para los estudios del afecto y que han comprometido la lógica del Giro Afectivo en las ciencias sociales con una filosofía de los procesos.

Hay que decir que Deleuze, Bergson y Whitehead no son los únicos filósofos que han tenido influencia en los estudios del afecto; aunque no hablaré de ellos, es imprescindible reconocer la importancia de la obra de filósofos y pensadores como Jaques Lacan, Felix Guattari, Michael DeCerteau, Lawrence Grossberg, William McDougall, John Dewey, incluso Friedrich Nietzsche, y por supuesto William James y su especulación filosófica-experimental, con la que este artículo queda en grandísima deuda. A pesar de que las ideas de estos autores han influido en los estudios del afecto, su contribución no radica en consolidar una filosofía de los procesos -Spinoziana- como piedra angular de los estudios contemporáneos del afecto y por lo tanto no abordaré sus contribuciones. En cambio, aquí vamos a revisar los aspectos del pensamiento de Guilles Deleuze que dieron lugar a teorías como la Autonomy of affect (Massumi 1995); los planteamientos de Henri Bergson que posibilitaron una New philosophy for new media (Hansen 2006); y la filosofía de los procesos relacionales de Alfred N. Whitehead que ha servido de base para el desarrollo de teorías como Liminality and affectivity de Paul Stenner y Eduard Moreno (2013).

El propósito de este texto es presentar las principales ideas de estos tres filósofos para lograr esbozar las líneas que sus pensamientos han generado en los estudios contemporáneos del afecto; y aproximarnos así a una mejor comprensión de las teorías que regresan a estas filosofías de los procesos en busca de perspectivas más amplias sobre el afecto. Esta vuelta filosófica es la que permite el toque retro y a la vez de vanguardia, que es el sello del 'Giro Afectivo'. Su gesto vintage, a medio camino entre la nostalgia y la esperanza.

\section{De Gilles Deleuze a la Autonomía del Afecto}

No hay que esforzarse demasiado para evidenciar la huella de Spinoza en la filosofía de Gilles Deleuze; él mismo caracterizó su obra como Spinoziana y dedicó dos libros a este tópico (Spinoza, practical philosophy y Expressionism in philosophy: Spinoza). Deleuze, como uno de los precursores del noesencialismo, desarrolló una filosofía centrada en la vida y la inmanencia que le es consustancial. En la filosofía de Deleuze, la importancia no está en los estados sólidos y definidos de las cosas, sean categorías psicosociales o biológicas (europeo, mujer, perro, adulta, pepino, etc.); sino en lo que sucede con dichos estados, aquello que los modifica. Su lógica no es la lógica del ser, sino del devenir. Al pensar las cosas -no como lo que son, sino como aquello que se están volviendo- Deleuze ofrece un cambio potencialmente radical, el salto de la esencia al proceso. Como lo explica lan Tucker: "por un lado se trata de un enfoque de no-reificación, pues si algo es un proceso y no una sustancia, entonces no es definido como una esencia estable que tenga la misma forma de actividad donde quiera que se encuentre. No hay nada único respecto a ella per se que por necesidad se mantenga constante en el tiempo" (2012a:772). 
Para Deleuze, un concepto clave en el cambio de las lógicas del 'sujeto' por las lógicas del 'devenir' es la idea de la potencia. Con ella se refiere a las cosas de las que un cuerpo es capaz y en virtud de las cuales la vida debería ser definida. Esto implica huir de la definición de los cuerpos basada en la especie a la que pertenecen, en busca de una descripción de los afectos de los que son capaces; para Deleuze la vida está ahí, en las cosas que de hecho hacemos y no en las que deberíamos hacer o en las que se supone que hacemos. Los efectos de dicha 'potencia' rebasan las fronteras físicas de los cuerpos, definiendo así una nueva frontera en función del alcance de la fuerza vital de cada cuerpo. A este nuevo perímetro variable de acción de la potencia particular de cada individuo Deleuze lo llamó territorio. El territorio está en modificación permanente, por eso es entendido como vector en movimiento con desterritorialización y reterritorialización constantes; Deleuze apunta que dichas desterritorializaciones sugieren un uso posible del cuerpo, uno que rompe el orden establecido y su organización, uno que propone un cuerpo sin órganos, sin organización. Pero las variaciones del territorio están en función de los encuentros que cada cuerpo tenga. Para Deleuze cada ser vivo -y no vivo- es atravesado por encuentros, encuentros más o menos convenientes, que amplían o reducen su territorio, al maximizar o minimizar su potencia, es decir, encuentros que afectan a los cuerpos que atraviesan. Ahora bien, el foco en estos encuentros y las modificaciones del territorio que de ahí se desprenden dan lugar a la idea del devenir como una lógica generalizada de la existencia, como una dinámica de la vida en cuyo proceso estamos inmersos. Esta idea es la que sostiene una filosofía interesada en aquello que aún no somos, aquello que esta por suceder(nos).

Para explicar lo que sucede -y lo que aún no sucede- en estos encuentros, Deleuze desarrolla la distinción entre lo virtual y lo actual. En esta distinción lo actual "es ese aspecto de los movimientos, fuerzas y relaciones que somos capaces de comprender en un punto particular" (Brown y Stenner 2009:185, traducción propia); y lo virtual es la potencia de actualización, es, por decirlo de algún modo, el conjunto de los resabios de las capacidades de los cuerpos que no se actualizan en el encuentro, pero que está potencialmente ahí, como parte del territorio. El punto crucial aquí es que no hay una transición lineal que conduzca los estados de las cosas de lo virtual a lo actual. Lo actual, para Deleuze, es más bien "la representación de lo virtual como un estado específico de las cosas en el que está implicado. Lo actual es extraído de lo virtual" (Brown y Stenner 2009:185, traducción propia). El devenir de los cuerpos es, entonces, explicado por Deleuze en esta tensión virtual/actual; para él "lo virtual, (está) rodeando lo actual, perpetuamente renovándose a sí mismo, emitiendo otros, de los que a su vez está rodeado y que a su vez van a reaccionar sobre lo actual" (Deleuze, citado por Brown y Stenner 2009:185, traducción propia, paréntesis propio).

Una distinción que es necesario precisar en el combo virtual-actual, es la relación que Deleuze establece entre la mente y el cuerpo. Para él, el foco crítico está en los desplazamientos corpóreos, en el movimiento entre los estados del cuerpo que son su intensidad; por lo tanto sugiere que "la mente comienza por relacionar lo que el cuerpo hace fría y curiosamente, es ante todo un testimonio, entonces se ve afectada, se convierte en un testigo apasionado, esto es, experimenta por si misma afectos que no son simples afectos del cuerpo, sino entidades críticas veraces que se ciernen sobre el cuerpo y lo juzgan" (Deleuze 1997:124). Massumi desprende de esta idea que el cuerpo y la mente están así unidos pero separados, potencialmente desarrollados en diferentes direcciones, afectados de manera diferente. 
"El cuerpo no solo absorbe pulsos o simulaciones discretas; sino que despliega contextos, despliega voluntades y cogniciones que no son nada sino están situadas. La intensidad es asocial, pero no presocial" (1995:90). De manera que la mente y el cuerpo, pero además y en general la idealidad y la materialidad, brindan instantáneas posibles a partir de esta dinámica virtual/actual. En las palabras del propio Deleuze: "cuando el contenido virtual de una idea es actualizado, las variedades de relación son encarnadas en especies distintas, mientras que los puntos singulares que corresponden a los valores de una variedad son encarnados en las distintas partes características de tal o cual especie" (Deleuze 1994:206, traducción propia). Esta idea provee un insight para pensar a través del cuerpo de una manera no esencialista que permanece fiel a muchos niveles y modos diferentes de la experiencia corporal.

Ahora bien, la virtualidad que sugiere el devenir se actualiza solo a partir de disposiciones concretas de lo ya actualizado. Esto nos lleva a otro concepto Deuleziano importante: los conjuntos (assemblages). Podemos definir un conjunto como una disposición particular de los cuerpos, relaciones y afectos. $\mathrm{O}$, como Deleuze y Guattari lo ponen, una "longitud y latitud, un conjunto de velocidades y lentitudes entre partículas sin forma, un conjunto de afectos no-subjetivizados" (2014:262). Si bien, estos conjuntos nosubjetivizados, no lo son aún, se lo deben en parte a que siempre queda un trecho de remanencia, algo de lo virtual de lo que lo actual no alcanza a dar cuenta. En esta filosofía, dicha condición de perpetuas remanencias que no pueden ser capturadas o explicadas -ni actualizadas con independencia del conjunto- son entendidas como singularidades. Halewood ha señalado que la importancia de las singularidades en la obra de Deleuze radica en que estas "representan la distribución diferencial dentro de lo que él llama lo 'virtual', que no es actualizado como diferente, no es individualizado" (Halewood 2005:68).

En la filosofía de Deleuze, esta incertidumbre en los pliegues de lo virtual y lo actual, estos conjuntos que la condicionan, la potencia de los cuerpos y sus territorios, son nada menos que la vida misma. Una vida, escribe Deleuze, "contiene solo entidades virtuales. Está compuesta de virtualidades, eventos, singularidades. Lo que uno llama virtual no es algo ausente en la realidad" (2007:224). Deleuze escribe en uno de sus textos más densos Immanence: a life (recopilado en el libro Two regimes of madness), que uno debe comenzar por un mundo en el que la conciencia aún no se revela, aunque es co-extensiva con la totalidad del campo trascendental. "Uno no puede establecer distinciones dentro de ella: ni de sujeto ni de objeto" (2007:224). Como hemos visto hasta aquí, la propuesta Deuleziana está Ilena de vocabulario propio, y es que para Deleuze la tarea de la filosofía consiste en la invención de conceptos. Así, como reconocen Brown y Stenner (2009), intentar esbozar la obra de Deleuze nos mueve de la fuerza impersonal de la inmanencia pura, al circuito de lo virtual y lo actual, a la territorialización y desterritorialización de los conjuntos en la sombra del cuerpo-sin-órganos. La subjetividad y la determinación de nuestra vida individual dependen de esos procesos. Estas breves líneas representan reducción somera y por demás injusta para de la obra de Gilles Deleuze, sin embargo, escribo estas ideas para introducir el cambio que su pensamiento ha generado en los estudios del afecto. Deleuze, fue el primer filósofo al que recurrió el Giro Afectivo, a través del trabajo de Brian Massumi y su texto parte aguas The Autonomy of Affect (1995). 
Massumi explica extensamente por qué la elaboración de Deleuze del concepto de lo virtual es tan central para su trabajo y por qué sostiene una gran promesa para la teoría social y cultural de hoy en día. Para Massumi lo virtual es una forma de considerar la indeterminación y la apertura de sistemas respecto a los agentes individuales que sirven como los puntos focales a través de los cuales actúan. En otras palabras, "lo virtual es una forma de pensar la relación y el paso de la multiplicidad a la individualización" (Brown y Stenner 2009:184). La distinción que Deleuze hizo entre lo actual y lo virtual fue la clave sobre la que Massumi fundó la diferencia entre afecto y emoción. Bajo esta lógica, lo indeterminado, lo que está aún por suceder, sería el campo de acción de lo que Massumi identificara como el afecto; mientras que la actualización de dicho afecto, su identificación, extrapolada además a los terrenos de la conciencia, sería la emoción para Massumi, de manera que afecto y emoción "siguen diferentes lógicas y pertenecen a diferentes órdenes" (1995:88). Esta distinción crucial para el Giro Afectivo no es otra cosa que la toma de Massumi de la dupla virtual-actual Deuleziana y su traducción a la estratificación de diferentes niveles de la experiencia afectiva (sentimiento-emoción-afecto).

Para Massumi, argumentar una distinción entre afecto y emoción requiere mirar fuentes filosóficas distintas: "no es que no haya antecedentes filosóficos en los cuales basarse. Es solo que no son los usuales para la teoría cultural" (1995:88). Así Massumi recurre a Deleuze porque encuentra en él la reapertura del camino que comenzó Spinoza para repensar el cuerpo en relación con el afecto. El clímax de la distinción virtual-actual y su traducción en términos de afecto-emoción, es alcanzado por Massumi cuando propone la Autonomía del Afecto; esta se refiere a la "participación simultánea de lo virtual en lo actual y de lo actual en lo virtual, en tanto que uno se origina en y regresa al otro" (1995:96). El afecto para Massumi, son "perspectivas virtuales sinestésicas ancladas en (y funcionalmente limitadas en) las ya existentes cosas particulares que las encarnan. La autonomía del afecto es su participación en lo virtual. Su autonomía es su apertura" (1995:96, traducción propia, cursivas y paréntesis del original). El afecto, continua Massumi, "es autónomo en el grado en el que escapa del confinamiento en el cuerpo particular cuya vitalidad, o potencial para la interacción, es" (1995:96). En esta perspectiva la traducción de dicho afecto a su correlato perceptual y cognitivo representan la emoción. O cómo él mismo lo dice: "La emoción es la expresión más intensa (más recurrida) de esa captura -y del hecho de que algo ha siempre y de nuevo escapado. Algo permanece sin actualizarse, inseparable de, pero inasimilable a, cualquier perspectiva particular funcionalmente anclada" (1995:96, traducción propia, paréntesis y cursivas del original). Como corolario de esta perspectiva Massumi sostiene que "las cosas reales existentes y estructuradas viven en y a través de aquello que se les escapa. Su autonomía es la autonomía del afecto" (1995:97).

Ahora bien, de la mano de Deleuze, Massumi establece un vínculo con algunas expresiones de la física cuántica y la mecánica cuántica como el trabajo de Bohm; para indagar en la relación entre lo virtual y los niveles de organización fuera de la percepción, es decir, los subatómicos o cuánticos, que implican una mediación no-física entre lo actual y lo virtual. Este vínculo ha permitido que una línea de estudios del afecto con base en esta lectura Deleuziana de Massumi desarrolle además un reencuentro con otras disciplinas como la biología molecular o las matemáticas de la información e incluso las neurociencias. Aunque después de la propuesta de Massumi los estudios del afecto inspirados en la obra de Deleuze se han diversificado, es común que la inspiración Deuleziana nos lleve a abordar el afecto de formas 
necesariamente más amplias que las circunscritas únicamente a los procesos perceptuales. De la mano de Deleuze, el afecto aparece siempre como un exceso autónomo con una virtualidad dinámica inmanente.

\section{De Bergson a la filosofía de la media}

Nuestro siguiente filósofo de los procesos con gran influencia en el Giro Afectivo es Henri Bergson. Según Elizabeth Grosz: "Para Bergson, "la filosofía aporta al conocimiento lo que las ciencias necesariamente dejan a un lado, es decir, las continuidades y las conexiones que la ciencia no puede ver en su preocupación por los sistemas cerrados, así como los términos definibles y aislados" (Grosz 2005:4). Entonces, su proyecto filosófico se propone superar los errores simétricos del idealismo y realismo al generar un sistema que entienda a la percepción como algo que se deduce a partir de la materia; o, como lo entiende Elizabeth Grosz, es "el reemplazo de conceptos estáticos de las cosas a través de la creación de concepciones dinámicas de procesos en continua transición" (2005:10). Para movilizar este proyecto, sugiere Grosz, Bergson se preocupa por tres transformaciones simultáneas: la del concepto del 'ser' a través de la generación de una ontología del devenir, la de lo actual en términos de la elaboración de lo virtual, y la de la inteligencia a través de la intervención de la intuición. El eje analítico común de estas tres transformaciones, será, para Bergson, la percepción del tiempo.

Pero antes de abordar la percepción y el tiempo, quizá es preciso introducir a Bergson a partir de la metodología que desarrolló para sistematizar -si acaso cabe el término-su pensamiento: la intuición. La intuición Bergsoniana se refiere a un "método filosófico riguroso para la sintonía con las especificidades concretas de lo real. La intuición es el método por el cual son creados conceptos únicos y originales y desarrollados para los objetos, cualidades y duraciones que son únicas y especificas en sí mismas" (Grosz 2005:7). Esta preocupación por las particularidades y las diferencias de las cosas condujo a Bergson directamente al debate entre lo objetivo y lo subjetivo; pero, en un giro brillante, él recurre al concepto de lo virtual para marcar la distinción entre lo subjetivo y lo objetivo. Como lo explica Ansell-Pearson, Bergson "invierte la manera en que normalmente pensaríamos esta distinción, con lo 'subjetivo' denotando cualquier cosa que se tenga completa y adecuadamente sabida y lo 'objetivo' aplicado a lo que es sabido en una forma que reconoce nuevas impresiones y que pueden ser sustituidas y agregadas a nuestra idea de esa cosa" (Ansell-Pearson 2002:4). Así, lo objetivo contiene a lo virtual y es por lo tanto el objeto mediante el cual la intuición puede aproximarse a las particularidades de las cosas. Como el eje que articularía los intereses Bergsonianos en la percepción y el tiempo, la noción de lo virtual fue una constante en su obra, apareció por primera vez en Time and Free Will, aunque será retomada y desarrollada en Matter and Memory y en Creative Evolution.

Para Bergson, tradicionalmente vemos el tiempo "de acuerdo a las categorías medibles de pasadopresente-futuro (...) esto es una simplificación que aboga por un modelo linear de tiempo en el que pasado-presente-futuro existen en una línea de dimensiones exactas de tiempo (minutos, horas, días, semanas)" (Tucker 2012b:501, traducción propia, primer paréntesis propio, segundo paréntesis del original). En lugar de eso, Bergson ve pasado-presente y futuro como parte de una sola temporalidad que se expresa en el presente. El pasado y el futuro son imágenes (ya ocurridas o previstas) evocadas en 
el presente, son dos aspectos de la construcción de la experiencia psicológica de la vida presente. Entonces, la importancia no se coloca en ninguno de los tres - pasado, presente o futuro- por encima de los otros; sino en su condensación: la duración. La idea Bersoniana del tiempo es la de un tiempo que no se experimenta cronológicamente, sino como una totalidad. Bergson afirma que el tiempo es duración y es "pura y simplemente lo que yo siento y lo que yo veo" (2005:18). La experiencia psicológica del tiempo en la filosofía de Bergson no es una experiencia linear. En lugar de eso, la experiencia es duración, un proceso de vida complejo que relaciona diversas temporalidades: el pasado en forma de memoria y el futuro en forma de expectativa.

Como lo explica Grosz, la cualidad duracional que el universo posee en la filosofía Bergsoniana es lo que permite que las cosas estén sincronizadas, es decir, "temporalmente mapeados en relación unos a otros, divisible en diferentes flujos y -al mismo tiempo- capaces de participar en una sola dirección englobada y actual" (Groz 2005:11). Lo real aquí es entendido como duracional y "está compuesto de millones incluso billones de duraciones específicas, cada una con sus propias medidas, sus propios lapsos. Sin embargo cada duración puede ser vinculada a las otras porque cada una participa en la totalidad de la duración y lleva en ella el flujo duracional, es decir, una orientación irresistible hacia delante y un impulso a complejizar en este movimiento" (Grosz 2005:11, traducción propia). La idea de tal impulso ineludible nos conduce a la conceptualización de la vida en términos de un 'ímpetu', o élan vital impulso vital-, que Bergson desarrolló en Creative Evolution.

Si junto con Bergson, asumimos que lo real contiene -incluso es- una duración múltiple o como él lo concibe explícitamente una multiplicidad virtual (virtuellement multiple), estaríamos dispuestos a aceptar que la duración de un cuerpo, por ejemplo, abarca y revela otras duraciones. Esto es así porque para Bergson, lo real es construido como fundamentalmente dinámico, complejo, con final-abierto, a causa del devenir. Dicha duración variable inmanente y constante es lo que Bergson llamó una 'multiplicidad virtual' y que, aplicada a la comprensión del tiempo y la duración permite que estos no se vuelvan un asunto de lógica o matemática, sino más bien la comprensión de un proceso de engranaje de múltiples temporalidades que residen en los cuerpos y la materia y que se despliegan y contraen en una situación dada.

Ahora bien el intervalo de duración existe solo para nosotros y debido a la interpretación de nuestros estados conscientes. "La duración y el movimiento no son objetos sino 'síntesis mentales"' (Bergson 2001:120). Partiendo del principio Spinoziano de que el cuerpo es el objeto de la idea de la mente, esta duración mediada y a la vez contenida en la conciencia conduce a Bergson a hablar de la percepción necesariamente atravesada por el cuerpo: una percepción encarnada. Para sostener esta idea, él postula que el mundo está compuesto por un agregado de imágenes, y la percepción demarca la selección de un subconjunto de este agregado a través de un centro de indeterminación, que es el cuerpo. En la filosofía de Bergson, el cuerpo funciona como una especie de filtro que selecciona, de entre el universo de imágenes circulando alrededor de él y de acuerdo con sus propias capacidades corporales, precisamente aquellas que son más relevantes para él. Lo que es más, en Matter and Memory, Bergson coloca su énfasis en el cuerpo como una fuente de acción; así, es la acción del cuerpo la que sustrae la imagen relevante del flujo universal de imágenes. El intervalo de duración interpretado por esta percepción 
encarnada, incluye por supuesto las imágenes derivadas de la materia. Como sugiere Grosz, en la filosofía de Bergson "la materia es la duración en su versión más dilatada, la materia es duración en tanto que es experimentada, en su variedad de grados o cualidades de expansión o contracción. La vida es la prolongación de la materia, como la materia es la contracción de la vida (...) más que términos binarios, son grados diferentes de duración, tensiones diferentes, modos de relajación o contracción, ni opuestos ni continuos - matices diferentes, diferentes actualizaciones de una y la misma cosa, esto es, la duración siempre diferente, interna y eternamente difiriendo" (Grosz 2005:6, traducción propia, paréntesis propio).

La diferencia fue el concepto utilizado por Bergson para referirse a la dinámica anti-esencialista a través de la cual las cosas devienen. Las cosas que duran en el tiempo devienen otra cosa, así que la duración es una expresión de la diferencia. Además, cuando estas cosas duran en el tiempo se vuelven algo diferente a lo que eran antes, a esta operación del devenir de las cosas, Bergson la llamó autodiferenciación. La duración es así la condición de posibilidad de la diferencia. Grosz sugiere que "en la medida en que la duración implica un futuro abierto, implica la elaboración y la apertura del pasado y el presente de lo que es virtual en ellos, de lo que en ellos difiere de lo actual, de lo que en ellos puede producir la novedad. Este des-devenir es el motor del devenir, haciendo el pasado y el presente no dados sino fundamentalmente siempre-alterando lo virtual' (2005:4, traducción propia). A partir de esto, la multiplicidad, como Bergson explica en Creative Evolution, se refiere al hecho de que la duración no es continua, por el contrario, refiere a una constante creación de novedad.

La filosofía Bergsoniana es uno de los esfuerzos anti-esencialistas más acabados, en el que el universo entendido como un ente duracional nos lleva a pensar en aquello que las cosas comienzan a ser mientras duran, su devenir, y el papel que tienen el cuerpo y la conciencia en la experiencia que tenemos las personas respecto a esos devenires, a los sucesos de la realidad y su orden en el tiempo. Ahora bien, la preocupación de Bergson por la forma en que percibimos el tiempo y su abordaje de la naturaleza en términos de 'duración' es lo que vuelve a su filosofía un arsenal de municiones para los teóricos interesados en desgranar los recovecos de una era con nuevas temporalidades, en la que las nuevas tecnologías introducen lapsos temporales a nuestra cotidianeidad que promueven nuevas formas de sensibilidad, algunas de las cuales permanecen aún por ser explicadas; pero este camino se ha empezado a recorrer por teóricos del afecto en las tecnologías de new media como Mark Hansen.

Para desarrollar una explicación del embodiment de la new media, Hansen propone reconsiderar la teoría de la percepción de Bergson, y en particular, tomar seriamente el énfasis de Bergson en el cuerpo como lo que Hansen llama un centro de indeterminación al interior de un universo sin centro. Para Hansen, Bergson permanece sobre todo como un teórico de la percepción encarnada, a partir de sus conceptos centrales de afecto y memoria con los que correlaciona la percepción con la vida concreta del cuerpo. Inspirado por Bergson, Hansen apuesta por reconfigurar la percepción como una disminución o substracción del universo de imágenes; así, "lo que distingue mi percepción de un objeto material de un objeto que no es en sí mismo algo interno para mi cerebro o algo agregado por mí, pero el hecho de que pueda percibirlo solo al aislar algunos de sus aspectos, dejando el resto aparte" (Hansen 2006:4, traducción propia). Como Hansen lo entiende, si el cuerpo afectivo es capaz de modificar y decidir sobre 
los aspectos importantes de una imagen, podrá también "legítimamente condicionarse su propia deducción a partir del universo de imágenes" (2006:5). Si el cuerpo es capaz de sustraer imágenes del mundo y si a partir de esas imágenes representamos el mundo, entonces el cuerpo afectivo se coloca en el centro de la deducción general de la percepción, en la que "una imagen puede ser sin ser percibida puede estar presente sin ser representada- y en la distancia de estos dos términos, presencia y representación, parece justo medir el intervalo entre la materia misma y nuestra percepción consciente de la materia" (Bergson 2005:35, traducción propia, guiones del original).

Para traer el afecto Bergsoniano al terreno de la tecnología, según Tim Lenior: "Hansen argumenta que la convergencia de la media sobre la digitalidad en realidad incrementa la centralidad del cuerpo como marco de información: como la media pierde su especificidad material, el cuerpo toma una función más prominente como procesador selectivo en la creación de imágenes" (Prólogo de Lenior en Hansen 2006:xxi). Como se puede leer en New Philosophy for New Media (Hansen 2006), para esta perspectiva, las características procesuales e interactivas de la imagen digital proveen bases para remplazar las nociones de tiempo-imagen y movimiento-imagen descritas por Deleuze y que es uno de los principales objetivos de la obra de Hansen. Para tal efecto, Hansen recurre a la resucitación y actualización de la noción de función de enmarcación primaria del cuerpo de Bergson al alinearla con desarrollos recientes en tecnología de la información y new media art. Hansen argumenta que cada régimen de imagen, incluyendo el digital, esta primeramente enmarcado por una conexión 'embriogénica' con el cuerpo humano. En la versión de Hansen, la producción de la imagen está entonces correlacionado con el cuerpo, de hecho, inscrito en el cuerpo como pantalla. La 'vocación Bergsoniana' de Hansen afirma que no hay información (o imagen) en la ausencia del potencial dador-de-forma de la in-corporación humana.

Al hacer su argumento Hansen se basa selectivamente en el trabajo de artistas de new media -sobre todo en el trabajo de Bill Viola- "que destacan en el cambio de lo visual a lo afectivo, háptico, y registros propioceptivos cruciales para reciclar el pensamiento Bergsoniano" (Prólogo de Lenior en Hansen 2006:xxiii). Lo que es más relevante de la filosofía de Bergson para los desarrollos de Hansen es la forma en que para él, el cuerpo y el afecto actúan como un conector entre la conciencia y diversos procesos sensoriomotores y subperceptuales. Es a través de este canal afectivo que Hansen quiere vincular materialmente el flujo de la información en la imagen digital y el cuerpo como marco; en este punto Hansen recurre a las neurociencias de Francisco Varela para optar por una comprensión del tiempo como un "flujo generado endógenamente basado en capas de ensamblajes auto-organizados y dinámicos de neuronas" (Prólogo de Lenior en Hansen 2006:xxv). Además, Hansen recurre a Varela porque para él, el flujo temporal está ligado al afecto y de hecho lo precede, constituyendo así un enlace entre el tiempo y su representación o percepción. A partir de esto, Hansen sostiene que el new media art demuestra cómo el cuerpo afectivo y sensoriomotor sirve para catalizar y enmarcar información al interior de imagen digital percibida por humanos. Pero estos aportes que ahora marcan tendencia en los estudios de media y en general en los estudios contemporáneos del afecto requirieron del reciclaje de la teoría de la percepción de Bergson, su interés por el cuerpo como centro de indeterminación y por supuesto, su apuesta por el afecto como dinamizador de las duraciones que constituyen el mundo real. Para Hansen, deberíamos, en resumen: "permitir el ahora de la percepción devenir contaminado con 
afección; debemos identificar el ahora con el umbral dentro del cual la percepción del flujo de un objeto afecta -se afecta a sí misma y por lo tanto genera una percepción suplementaria, una percepción del flujo mismo, tiempo-conciencia" (Hansen 2006:602).

Además de la renovación que Hansen hace de la filosofía de Bergson, en el panorama contemporáneo de los estudios del afecto también se pueden encontrar otro tipo de trabajos, en relación a media y a otros temas que reciclan las ideas de Bergson; este sería el caso de los trabajos de Keith Ansell-Pearson (2002) o de lan Tucker (2012 a y b), ambos en relación a la percepción y organización del tiempo. La presencia del Bergson en los estudios del afecto nos lleva invariablemente a la reconsideración de la percepción y sus procesos paralelos en las dinámicas afectivas; Bergson nos incita a pensar en el tiempo y el cuerpo como el dispositivo en el que dicho tiempo se encarna y se siente.

\section{De Alfred N. Whitehead a la experiencia liminal}

Alfred North Whitehead fue un destacado matemático y filósofo inglés, su obra ha sido tan notable que se le ha reconocido como la gran mente especulativa del siglo XX. Aunque Whitehead publicó avances en matemáticas, física, filosofía de la ciencia, religión, educación, metafísica, entre otras; la parte de su trabajo que ha influenciado los estudios del afecto es la relacionada con su ontología de los procesos relacionales. De cierta manera, dicha ontología representa una síntesis de los aspectos más representativos de su obra y perfila la misma como centrada en el afecto.

Whitehead, no menos que Spinoza, tenía la intención de argumentar en contra de lo que él describió como la bifurcación de la naturaleza. La obra de Whitehead estuvo caracterizada por su insistencia en que la ciencia, la filosofía, las humanidades y la teoría social requerían todas una renovación de la concepción de la naturaleza (en el sentido más amplio de la palabra), una que fuera más allá de las limitaciones científicas estrictas, más allá de cualquier forma de esencialismo biológico o que no dependiera de cualquier noción de las leyes últimas de la física o la naturaleza. Whitehead tuvo como objetivo desarrollar un concepto de naturaleza que fuera capaz de incorporar todas las existencias y así poner juntas la empírica, material, social, estética y la de los seres pensantes. Stenner explica que Whitehead estableció una distinción entre dos formas muy diferentes de aproximarse al estudio de la naturaleza: el empiricismo superficial y el empiricismo profundo; en donde este último era la alternativa para superar la bifurcación de la naturaleza. Whitehead desarrolló un "empiricismo profundo que extiende y redefine radicalmente el dominio de la subjetividad (...) en el empiricismo profundo ni el sujeto ni el objeto desempeñan el papel de primer término o sustancia primaria. Por el contrario, (...) el primer término es siempre la ocasión actual (...) que es siempre una fusión del sujeto y el objeto en el evento unificado de la experiencia (Stenner 2008:94, traducción propia, cursivas del original, paréntesis propios).

Este evento de experiencia fue nombrado por Whitehead ocasión real (actual occasion). En sus palabras: "Si vamos a buscar la sustancia en cualquier lugar, yo la encontraría en los eventos que son en algún sentido la última sustancia de la naturaleza" (Whitehead 1985:19). Stenner aclara que "para 1927-1928 la terminología de Whitehead había cambiado de 'evento' a 'entidades/ocasiones reales' con esta última definida como 'el tipo limitado de evento con un solo miembro'" (Stenner 2008:98, traducción propia, 
comillas del original). El concepto de ocasión real como 'átomo' de experiencia requiere un concepto suplementario, es decir, la agrupación de ocasiones actuales en lo que Whitehead llama sociedades y nexos de ocasiones reales. Como Stenner señala, la importancia de esto radica en que el evento de una ocasión actual no es algo que dure en el tiempo, a diferencia de los assemblages Deleuzianos o la propia duración Bergsoniana: “Una ocasión actual, en la filosofía de Whitehead, no es algo con una historia y por lo tanto no es algo que cambie. Es algo que se vuelve, que deviene, y después perece. Es un evento momentáneo de la experiencia. Es, en este sentido, atómico. En otras palabras, las cosas completamente reales no duran en el tiempo" (Stenner 2008:100).

Con las 'ocasiones reales' como el aspecto atómico de la experiencia y las 'sociedades' o 'nexos' como el aspectos de continuidad, la filosofía de Whitehead nos brinda la posibilidad de abordar lo que Stenner reconoce como "diferentes tipos o grados de ocasión actual operando en una variedad de niveles de complejidad ofrecidos por diferentes formas de ensamblaje". En el grado más alto, avanza Stenner, "algunos de estos ensamblajes albergan los tipos de ocasiones que asociamos con las complejidades de la mentalidad humana, y en el grado más bajo albergan los tipos de ocasiones repetitivas asociadas con las ciencias físicas. Pero todos son eventos que comparten la relación básica sujeto/objeto de una ocasión actual de experiencia" (2008:101). Esto no implica en ningún caso que todos los niveles de ensamblaje son lo mismo -como un trueno o una célula-, más bien, como lo entiende Debaise: "la diferencia entre los varios niveles de ensamblaje no debería ser buscada en esencias particulares sino en trayectorias" (Debaise 2013:104). Ahora bien, el proceso mediante el cual se generan estos ensamblajes en la filosofía Whitehediana es la prehensión. Este término se refiere a cómo una entidad actual aprehende su medio ambiente. Las prehensiones son un elemento crucial en el pensamiento de Whitehead: son el medio por el cual él explica el carácter absolutamente relacional de la existencia; ellas (las prehensiones) describen el pasaje por el que todas las entidades están relacionadas. Whitehead utiliza el término prehensión "para la forma general en la que la ocasión de la experiencia puede incluir, como parte de su propia esencia, a cualquier otra entidad" (Whitehead 1967:234, traducción propia). Para Whitehead, la aprehensión es pura actividad. Como sugiere Jon Mills, es entonces equivalente al sentimiento: "es un acto valorativo, lleno de propósitos, auto-determinado" (Mills 2003:211).

En palabras de Whitehead: "Ser una entidad real es tener interés propio. Este interés propio es un sentimiento de auto-valoración; es un tono emocional" (1985:97). Whitehead explica que la aprehensión o sentimiento es la operación elemental de emerger de los datos objetivos a la forma subjetiva. Por lo tanto, una ocasión real viene a ser la sensación de la subjetividad fuera de la esfera de los objetos reales: "Los sentimientos son diversas operaciones especializadas, efectuando una transición hacia la subjetividad" (Whitehead 1985:40). Mills afirma que esta transición puede ser entendida como un proceso de actividad mental inconsciente: "una entidad está viva gracias al hecho de que siente y es sentida por otras entidades reales" (Mills 2003:213), es decir, las entidades tienen un carácter relacional. Al establecer este carácter relacional, Whitehead avanza en la disolución de lo que él llamó la bifurcación de la naturaleza, entendiendo todas las entidades como parte de un mismo proceso unificado. Para Whitehead todas las experiencias son emocionales. Esto incluye la experiencia sensorial desnuda; y también incluye modos de 'experiencia' que no son consciencia, y los no necesariamente humanos. En esta filosofía, los 'sentimientos' son idénticos a la 'prehensión positiva' en general, que son todas las 
formas en que las entidades interactúan entre ellas, o en que se afectan las unas a las otras. Sentir algo, para Whitehead -igual que para Spinoza- significa ser afectado por ese algo. Y la manera en que la entidad sintiente es afectada, o cambiada, es el propio contenido de lo que siente. Todo lo que sucede en el universo es entonces en algún sentido un episodio de sentimientos.

El afecto en la filosofía de Whitehead se encuentra en el centro de todos los eventos y cumple una función crucial en ellos. El afecto se entiende aquí como "el proceso de 'duplicación' por el cual los eventos que componen los tipos de organismos más básicos originan repetidamente eventos idénticos es, para Whitehead, un proceso de conformación de sentimiento" (Stenner y Greco 2013:67, traducción propia, comillas y cursivas del original). Sentir es este proceso que Whitehead denominó de 'síntesis creativa'. Sin embargo este proceso ocurre de manera diferente en los organismos más básicos y los más complejos. Stenner y Greco explican esta diferencia arguyendo que en "los organismos básicos, la novedad se mantiene al mínimo, y entonces los eventos físicos tienden meramente a repetir a sus precursores y contemporáneos" (2013:67); con los organismos complejos, avanzan Stenner y Greco, sucede algo distinto, ellos "negocian con la estabilidad de la mera supervivencia por la intensidad mayor de sentimientos posibles debido a la complejidad" (2013:67). En esta lógica, los organismos básicos "viven en el pasado, siendo determinado por la tradición", mientras que los más complejos "miran a un futuro aún no realizado en tanto que se sujeta a la inmediatez vivida del presente" (Stenner y Greco 2013:67, traducción propia).

Sin embargo, se trate de organismos básicos o complejos, para Whitehead toda prehensión es una forma de afectividad, es decir, "no hay nada en el mundo que sea meramente un hecho inherente. Cada realidad está ahí por el sentimiento: promueve sentimientos; y es sentida" (Whitehead 1985:41). A partir de esta idea, la filosofía de Whitehead ofrece una ontología de los procesos relacionales que promete una versión más profunda del construccionismo que no reduzca el universo a 'discurso' o 'significado subjetivo', y un empiricismo profundizado que no reduzca la naturaleza a materialidad sin significado. Como señalan Brown y Stenner, hay dos aspectos importantes a resaltar en la filosofía de Whitehead. Primero, "las cosas (físicas, biológicas, sicológicas o culturales) son definibles por su relevancia para otras cosas y en términos de la manera en que otras cosas son relevantes para ellas. Las cosas, en otras palabras, tienen una esencia relacional. En segundo lugar, las cosas no existen independientemente del tiempo sino que son constituidas por la historia de sus encuentros situados (sus procesos)" (Brown y Stenner 2009:12, traducción propia, paréntesis y cursivas del original). Ambos principios nos ayudan a entender que la filosofía de Whitehead está más interesada en la comprensión de los procesos que de la esencia; es decir, en lo que de hecho sucede más allá de la formación de cada ocasión real.

Ahora bien, esta ontología de los procesos relacionales ha generado diversas reflexiones al interior de los estudios contemporáneos del afecto: el ejemplo que aquí tomaremos es el estudio de Stenner y Moreno sobre la experiencia liminal. Stenner y Moreno realizan una actualización del concepto 'liminalidad' para complementar la noción de afecto que ha sido protagonista de los debates y desarrollos en el Giro Afectivo. Según estos autores, una aproximación al afecto desde la liminalidad puede considerarse una perspectiva Whiteheadiana, porque la idea de liminalidad "se trata de experiencias umbrales de transición entre estados, estructuras y patrones. El afecto sería entonces un fenómeno de transición o lo 
que los matemáticos Ilaman un 'vector'" (Stenner y Moreno 2013:238, traducción propia). La propuesta de Stenner y Moreno muestra además que la idea de liminalidad encaja con la definición ontológica de Whitehead de las 'ocasiones reales'. De hecho, el afecto para nuestros autores sería literalmente liminal: "Ios sentimientos, escribe Whitehead, 'son' 'vectores'; porque sienten lo que está ahí y lo transforman en lo que está aquí" (Stenner y Moreno 2013:238, traducción propia, comillas del original).

La apuesta de Stenner y Moreno por una afectividad liminal tiene detrás una preocupación sumamente pertinente en el panorama contemporáneo de los estudios del afecto: la disolución del privilegio del evento por encima de la estructura; y en consecuencia, el privilegio del afecto por encima de la emoción, y de los reinos infra-perceptuales por encima del mundo de los significados y los discursos. "El concepto de liminalidad puede entonces ayudarnos a articular una aproximación genuinamente orientada en los procesos, capaz de integrar el afecto y las tendencias orientadas al discurso abordando la estructura y el evento como aspectos del proceso analíticamente separables pero empíricamente siempre relacionados" (Stenner y Moreno 2013:238, traducción propia). Stenner y Moreno distinguen entre una liminalidad más antropológica, que atendería a los eventos sociales, y que "da más fuerza a la adquisición empírica de escenas reconocibles de la existencia humana" (2013:237); y una liminalidad ontológica que estaría "inclinada hacía un nivel elevado de abstracción porque debería ser aplicable a cualquier evento físico, biológico, psicosocial o sociológico" (2013:237). Dar una lectura desde la liminalidad a los fenómenos afectivos nos lleva a lo que nuestros autores han denominado una 'síntesis psicosocial más amplia' en la que el concepto de liminalidad puede complementar el de afectividad y así poner la atención en: "a) la ocasión social de determinadas experiencias intensas (o experiencias de intensidad), y b) en la importante (y paradójica) relación de esas experiencias con la estructura social" (Stenner y Moreno 2013:241, traducción propia, paréntesis del original).

Para Whitehead la naturaleza de las cosas es profundamente relacional, las cosas existen por su relevancia para otras cosas, y cuando las cosas entran en contacto con otras cosas, las cosas sienten y se reconfiguran en el proceso de prehensión; la afectividad, entonces, está siempre implicada en momentos de transición, y viceversa. En resumen, "si definimos la liminalidad como la experiencia de estar en, o atravesar por, un umbral, entonces empezamos a entender por qué los afectos y las emociones son fenómenos liminales de transición, y por qué las situaciones liminales son afectivas y emocionales" (Stenner y Moreno 2013:242, traducción propia). La afectividad, para Stenner y Moreno, debe ser comprendida como liminalidad ontológica. En esta perspectiva, los patrones estructurales, tanto del evento como de la experiencia, "son el resultado de múltiples, varios y recurrentes eventos de empatronamiento (ocasiones actuales de experiencia) en el curso en el que los 'datos' del mundo son patrones prestados a través de un proceso de sentimientos. Sentir no es solo una 'cualidad' de compañía sino literalmente un proceso de aprehender (prehension) en el que una ocasión/entidad actual le brinda un patrón a los datos heterogéneos de su mundo real dentro de una unidad" (Stenner y Moreno 2013:244, traducción propia; comillas, cursivas, énfasis y paréntesis del original). La idea de liminalidad vinculada a la ontología de los procesos relacionales de Whitehead y extendida a una liminalidad ontológica, es un recurso con mucho potencial para la solución de un par de conflictos que han acompañado a los estudios del afecto casi desde sus inicios, por ejemplo, brinda la posibilidad de comprender los vínculos entre los mundos infra-empíricos y los eventos sociales; como lo sugieren 
Stenner y Moreno: "La liminalidad puede entonces actuar como una bisagra teórico/metodológica articulando las complejidades abstractas del pensamiento abierto por los teóricos del afecto con el precepto etnometodológico de atender a las preocupaciones de los participantes que emergen de, por ejemplo, un trabajo etnográfico" (2013:246, traducción propia).

Ahora bien, la perspectiva liminal de Stenner y Moreno es un excelente ejemplo de los trabajos al interior del Giro Afectivo que utilizan y reciclan la filosofía de Whitehead, pero no es el único. Otros autores se han percatado del potencial de la filosofía Whitehediana para el estudio de la vida afectiva, y se ha desencadenado una serie de propuestas que coinciden con el espíritu crítico de la propuesta liminal. La característica común de los estudios del afecto inspirados en la filosofía de Whitehead radica en un interés por repensar las aproximaciones empíricas a los afectos y en general en el replanteamiento de las ciencias sociales. De cualquiera manera, la vida afectiva pensada desde Whitehead nos remite siempre a lo más profundo del entramado relacional de los eventos, de todos los eventos.

\section{Esperanzas vintage}

El regreso a las filosofías de los procesos relacionales ha sido el caldo de cultivo del re-encuentro con otras matrices de producción de conocimiento, no solo re-encuentros con la 'ciencia' dura, lo que en otro lugar hemos llamado 'esferas de articulación' (Lara y Enciso 2014); sino también las teorías del arte o las teorías psicoanalíticas. Estas filosofías evidencian la necesidad de una comprensión articulada entre lo social y lo físico/material, y más allá de eso establecieron la necesidad de una comprensión 'procesual' de los aspectos sociales de los fenómenos físicos y de los aspectos físicos de los fenómenos sociales. El pensamiento de estos filósofos puede ser aplicado en las ciencias sociales y proveer poderosas explicaciones de la relacionabilidad de la materialidad y la subjetividad en el mundo. $\mathrm{O}$ bien, como lo dice Whitehead, los aspectos mentales contenidos en la actividad de la materia, y de cualquier tipo de 'asociación' emergente. Esta mirada amplia es una de las características de los estudios realizados en el marco del Giro Afectivo. Como sugieren Brown y Tucker: "la mayor parte de la obra que es fundamental para el giro afectivo en las ciencias sociales ha buscado un nuevo espacio de libertad en lo 'inefable', en cambiarse a sí misma, en las relaciones afectivamente mediadas que no pueden ser contenidas en el pensamiento crítico existente. Este es un movimiento propiamente filosófico que se basa en algunos de los más sofisticados intentos de superar las abstracciones de la trascendencia con la vitalidad creativa de la inmanencia" (2010:248, traducción propia, comillas del original).

Una de las consecuencias más notorias del uso de estas filosofías guarda relación con las implicaciones éticas, políticas y de guvernamentabilidad sobre el cuerpo. Esto es, basándose en el rechazo Spinoziano de la división mente-cuerpo y luego entonces de la sujeción del cuerpo a la mente y del atributo del sujeto como activo y del objeto como pasivo, ha sido posible apuntar al potencial transformador de la materia y el cuerpo, y mirar de manera distinta las dinámicas de relación y control de unos sobre otros. Disolver la dualidad mente-cuerpo del proyecto Cartesiano, trae como consecuencia el replanteamiento político del control, la pregunta sobre quién o qué puede afectar sobre quién o qué. De ahí se desprende que una consecuencia del uso de las filosofías de los procesos sea el replanteamiento de la bio-política en relación al afecto. Si como dice Stengers, "una sociedad viviente debe ser comprendida en términos 
de preguntas que aborden explícitamente su carácter parcial: qué es la comida o el veneno para ella, qué le permitiría reproducirse, qué le proveería la oportunidad de sobrevivir, que la mataría" (2011:425, traducción propia). Entonces, el estudio del afecto está precisamente en aquellos procesos que ponen en juego capacidades, hábitos, dispositivos, acciones, etc., que movilizan el potencial de afectar o de ser afectado. Estos ítems relevantes son los que Latour definió como 'asuntos que importan', y para cuyo estudio, por cierto, propuso el empiricismo profundo de Whitehead como la salida más viable.

Los esfuerzos de Deleuze, Bergson y Whitehead por desarrollar lo que también podría llamarse una filosofía no esencialista, son de máxima relevancia para la academia contemporánea. Como sugiere Halewood esta es una época marcada por "el creciente foco en la interdisciplinariedad y el creciente reconocimiento de la necesidad de re-considerar la aparentemente irreconciliable dicotomía entre lo natural y lo social, la necesidad de moverse más allá de las explicaciones demasiado culturalistas o Foucaultianas de la subjetividad, la necesidad de renovar y desarrollar las interrelaciones de la ciencia y la filosofía" (Halewood 2005:58, traducción propia); bien, las filosofías de los procesos ofrecen notables intervenciones que pueden resultar fructíferas para investigadores y pensadores a lo largo de un rango de problemas. Estas filosofías invitan a la ciencia, la teoría social, y las humanidades a reconsiderar las asunciones ontológicas que subyacen a sus posiciones epistemológicas; por esa razón, el Giro Afectivo es esencialmente un giro ontológico que apuesta por alejar la producción de conocimiento de sus obsesiones epistemológicas. En este escenario, una importante consecuencia del reciclaje de nuestros filósofos es "la necesidad de la dramática consideración del estatus de ambas, la existencia física y la social al ir más allá de cualquier distinción simple entre los reinos de lo natural y lo social" (Halewood 2005:60, traducción propia). Así, el constante replanteamiento de las formas de producción de conocimiento no solo afecta a las ciencias sociales, sino también y como consecuencia de los reencuentros, a los otros nichos de producción de conocimiento como ha sucedido con las neurociencias de Antonio Damasio o las aproximaciones desde la teoría psicoanalítica de Blackman por citar algún ejemplo.

Sin embargo, la pluralización de la producción de conocimiento ha traído una consecuencia que, si bien no debería ser consustancial a las filosofías de los procesos, si ha acompañado a algunos trabajos que las utilizan de base filosófica y han sido de gran relevancia en el Giro Afectivo; me refiero claro, a la negligencia sobre algunos recursos de la producción de conocimiento propios de las ciencias sociales, y que, en pro de la búsqueda de aquello que está 'más allá' o de lo 'infra-empírico' se les ha excluido sistemáticamente de los estudios del afecto. Este menosprecio casi generalizado ha recaído sobre todo en las perspectivas y/o procedimientos comprometidos con la construcción del significado y los procesos del lenguaje que les son consustanciales. No obstante, mi sospecha es que profundizar aún más al interior de una filosofía de los procesos ayudará a llevar los estudios contemporáneos del afecto a un siguiente escaño en su producción teórica, es decir, a un nivel de producción de conocimiento empírico comprometido con las relaciones más íntimas y que paradójicamente disuelven la distinción entre el mundo físico/material y el mundo simbólico/estructural. Las filosofías de los procesos tienen el potencial de soportar conceptos y herramientas analíticas que nos permitan avanzar en la construcción de una ciencia social plural y en constante recreación. Desarrollar todo el potencial de una ciencia social de los afectos (y de cualquier cosa) basada en filosofías de los procesos nos permitiría avanzar en la producción 
de conocimiento a partir del análisis de datos empíricos, que hasta el momento, ha sido el talón de Aquiles del giro afectivo, y objeto de algunas de sus críticas. El compromiso con una filosofía de los procesos en la producción de las ciencias sociales nos permite incorporar -de nuevo- no solo los estudios del lenguaje, sino en general todo el arsenal de las ciencias sociales preocupadas por lo simbólico y la estructura social, no ya como fuente constructora de la realidad, sino como parte (relevante o no) del entramado en juego en la experiencia afectiva.

Un último apunte respecto a esta 'traducción' necesaria. Brown y Tucker señalaron que hay un problema en la relación que Deleuze lega entre las ciencias sociales y la filosofía en la que las ciencias sociales "se enfrentan a la elección de posicionarse a sí misma como ambas, la sub-empleada de la filosofía (una especie de antropología filosófica aplicada encargada de llevar los conceptos filosóficos auténticos al mundo) o una especie ciencia inferior" (Brown y Tucker 2010:241). Esta complicación existe también si se recurre a Bergson o Whitehead. En general y como apuntan Brown y Tucker: "el problema está en saber cómo relacionarse con el 'empirismo trascendental' de Deleuze junto a las formas más mundanas del empirismo que definen a las ciencias sociales" (2010:241, traducción propia, comillas del original). Para Brown y Tucker, la filosofía de Deleuze hace un trabajo de gran alcance al nombrar un problema filosófico en particular, es decir, cómo la experiencia puede ser sin-sujeto; podemos generalizar esta idea y afirmar lo mismo de filosofías como la de Whitehead y Bergson, en tanto que ambas apuestan por un cambio del ser al proceso. Pero como señalan Brown y Tucker este precepto "no puede ser traducido en su totalidad a los términos de las ciencias sociales sin una pérdida considerable de poder analítico" (2010:241, traducción propia). Para Brown y Tucker, las teorías del afecto que provienen de las filosofías de los procesos necesitan ser traducidas y adaptadas a través de un procedimiento muy particular con el fin de adquirir los objetos empíricos de la ciencia social. Como apuntan Brown y Tucker, las formas de empirismo que acompañan a las filosofías de los procesos, ya sea "el empirismo trascendental de Deleuze, el empirismo radical Jamesiano, la intuición Bergsoniana no pueden ser simplemente trasportados a las ciencias sociales y humanas al por mayor, sobre todo porque todas estas versiones de un método casi-idéntico ceden a la filosofía solo por sus autores. Cuando simplemente se trasponen, los resultados suelen mostrar indiferencia despreocupada de las particularidades de hacer ciencia social y como consecuencia no crean nuevos afectos ni nuevas experiencias" (Brown y Tucker 2010:248, traducción propia).

El reto que señalan Brown y Tucker a este respecto es el de "templar nuestro entusiasmo" y reconocer que "los conceptos intermediarios que la ciencia social inventa no pueden tener el alcance filosófico o la ambición buscada por el empiricismo trascendental. Deben ser más modestos, más aptos para las particularidades de los objetos con los que nos enfrentamos" (2010:248, traducción propia). Ese es el campo de acción de los estudios del afecto, "un giro desde el trabajo filosófico necesario de comprensión de la experiencia más allá de la subjetividad y hacia la construcción y el desencadenamiento de una serie de conceptos muy particular e individualizados que expliquen la complejidad de las experiencias pasadas a través de entornos socioculturales contemporáneos" (Brown y Tuker 2010:249, traducción propia). Esta es la marca del compromiso entre los estudios del afecto y las filosofías de los procesos en las ciencias sociales. Este es el gesto vintage de las teorías afectivas y sus nostálgicas vanguardias que comienzan a parecerse a la esperanza. 


\section{Bibliografía}

Ansell-Pearson, K. 2002. Philosophy and the adventure of the virtual: Bergson and the time of life. London: Routledge.

Bergson, H. 2005. Matter and memory. New York: Zone Books.

Bergson, H. 2001. Time and free will: an essay on the immediate data of consciousness. New York: Dover Publications, Inc.

Brown, S. y Stenner, P. 2001. Being affected: Spinoza and the psychology of emotion. International Journal of Group Tensions 30(1): 81-105.

Brown, S. y Stenner, P. 2009. Psychology without foundations: history, philosophy and psychosocial theory. London: Sage.

Brown, S. y Tucker, I. 2010. Eff the ineffable: affect, somatic management, and mental health service users. En: M. Gregg y G. Seigworth (eds). The affect theory reader. Durham: Duke University Press. pp. 229-249.

Clough, P. y Halley, J. (Eds.) 2007. The affective turn: theorizing the social. Durham, N. C.: Duke University Press Books.

Debaise, D. 2013. A philosophy of interstices: thinking subjects and societies from Whitehead's philosophy. Subjectivity 6(1): 101-111. doi: 10.1057/sub.2012.24

Deleuze, G. 1994. Difference and repetition. New York: Columbia University Press.

Deleuze, G. 1997. Essays Critical and Clinical. Minneapolis: University of Minnesota Press.

Deleuze, G. 2007. Two regimes of madness: texts and interviews, 1975-1995. New York: MIT Press.

Deleuze, G. y Guattari, F. 2014. A thousand plateaus: capitalism and schizophrenia. Minneapolis: University of Minnesota Press.

Enciso, G. y Lara, A. 2014. Emociones y ciencias sociales en el S. XX: la precuela del giro afectivo. Athenea Digital 14(1): 263-288. doi: 10.5565/rev/athenead/v14n1.1094

Gregg, M. y Seigworth, G. J. 2010. The affect theory reader. Durham: Duke University Press.

Grosz, E. 2005. Bergson, Deleuze and the becoming of unbecoming. Parallax 11(2): 4-13. doi: $10.1080 / 13534640500058434$

Halewood, M. 2005. On Whitehead and Deleuze: the process of materiality. Configurations 13(1): 57-76. doi: $10.1353 /$ con.2007.0009

Hansen, M. 2006. New philosophy for new media. Cambridge: The MIT Press. 
Lara, A. y Enciso, G. 2014. Ciencia, teoría social y cuerpo en el giro afectivo: esferas de articulación. Quaderns de Psicologia 16(2): 7-25. doi: 10.5565/rev/qpsicologia.1172

Lara, A. y Enciso, G. 2013. El giro afectivo. Athenea Digital 13(3): 101-119.

doi: $10.5565 / \mathrm{rev} /$ athenead/v13n3.1060

Massumi, B. 1995. The autonomy of affect. Cultural Critique 31: 83-109.

http://www.jstor.org/stable/1354446

Mills, J. 2003. Whitehead's unconscious ontology. Theory \& Psychology 13(2): 209-238.

doi: 10.1177/0959354303013002003

Stengers, I. 2011. Thinking with Whitehead: a free and wild creation of concepts. Cambridge \& London: Harvard University Press.

Stenner, P. 2008. A.N. Whitehead and subjectivity. Subjectivity 22(1): 90-109. doi: 10.1057/sub.2008.4

Stenner, P. 2011. James and Whitehead: assemblage and systematization of a deeply empiricist mosaic philosophy. European Journal of Pragmatism and American Philosophy 3(1): 101-130.

Stenner, P. y Greco, M. 2013. Affectivity. Informática Na Educação: Teoria \& Prática, 16(1): 49-70. http://seer.ufrgs.br/InfEducTeoriaPratica/article/view/36925

Stenner, P. y Moreno, E. 2013. Liminality and affectivity: The case of deceased organ donation. Subjectivity 6(3): 229-253. doi:10.1057/sub.2013.9

Tucker, I. 2012a. Deleuze, sense, and life: Marking the parameters of a psychology of individuation. Theory \& Psychology 22(6): 771-785. doi: 10.1177/0959354312442787

Tucker, I. 2012b. Organizing the present in anticipation of a better future: Bergson, Whitehead, and the life of a mental health service user. Theory \& Psychology 22(4): 499-512.

doi: $10.1177 / 0959354311424077$

Whitehead, A. N. 1967. Adventures of ideas. New York: The Free Press.

Whitehead, A. N. 1985. Process and reality. New York: Free Press.

Recibido el 15 Jul 2014

Aceptado el 29 Nov 2014 